\title{
Vertical migration of Mysis relicta Lovén
}

\author{
A. M. Beeton \& J. A. Bowers \\ Great Lakes and Marine Waters Center, The University of Michigan, Ann Arbor, MI 48109, U.S.A.
}

Keywords: Mysidacea, migration, review

\begin{abstract}
This review discusses the known features of diurnal vertical migration in the opossum shrimp Mysis relicta. Field observations describe a nocturnal pattern which is correlated to changing patterns of illumination. Hypotheses that offer evolutionary origins of vertical migration are presented which link trophic interactions of the migrator to their predators and prey. These couplings are examined for the case of Mysis relicta. All of the hypotheses are partially supported by Mysis behavior.
\end{abstract}

Interest in vertical migration of zooplankton extends back to at least 1817 when Cuvier observed diurnal changes in the vertical distribution of daphnids (Cushing 1951). Today it is well established that many marine and freshwater animals migrate vertically. These daily vertical movements either up or down, called diurnal, diel or noctural migrations show variations which can be related to age, sex and environmental conditions. Most studies have shown that response to light is an important factor in the migrations. Light has been considered from the standpoint of optimum intensity, change in intensity, phototactic response, control of geotactic response and by creating a sampling artifact which implied vertical migration. During daylight hours organisms could avoid visible sampling devices, while at night they could not (Holmquist 1959).

The literature on the vertical migration of mysids is not extensive. The first record is probably that made by Van Beneden (1861) when he observed that certain marine mysids swam to the surface even from deep water. The first actual record of a vertical migration, within the group, is that for Mysis mixta (Apstein 1906). Subsequently it was established that such migrations occurred nightly (Otterstrom
1910) and this has been documented for a number of species. Various authors have suggested that migrations of mysids were related to reproductive activity (Tattersall \& Tattersall 1951).

Dakin \& Latarche (1913) were the first to report that Mysis relicta, which had been considered a bottom dweller, became planktonic at night. Subsequently Southern \& Gardiner (1926) and Southern (1932) presented extensive field data wich demonstrated that $M$. relicta lived on or near the bottom during daytime but occurred at all depths at night. They were not able to establish a definite migratory pattern since they only captured 206 mysids at night and 74 during daytime throughout their 7-day study. Birge \& Juday (1927) observed vertical migrations of $M$. relicta in Green and Trout Lakes. Langford (1938) and Larkin (1948) made additional observations of migratory behavior. Larkin concluded from his sampling in Great Slave Lake that migration began at 10:00 p.m., reached a peak at midnight, and that few individuals remained near the surface until dawn.

The field studies by Beeton (1960) in two Great Lakes reaffirmed Larkin's observations and demonstrated a definite upward migration at darkness and gradual descent after the peak migration 


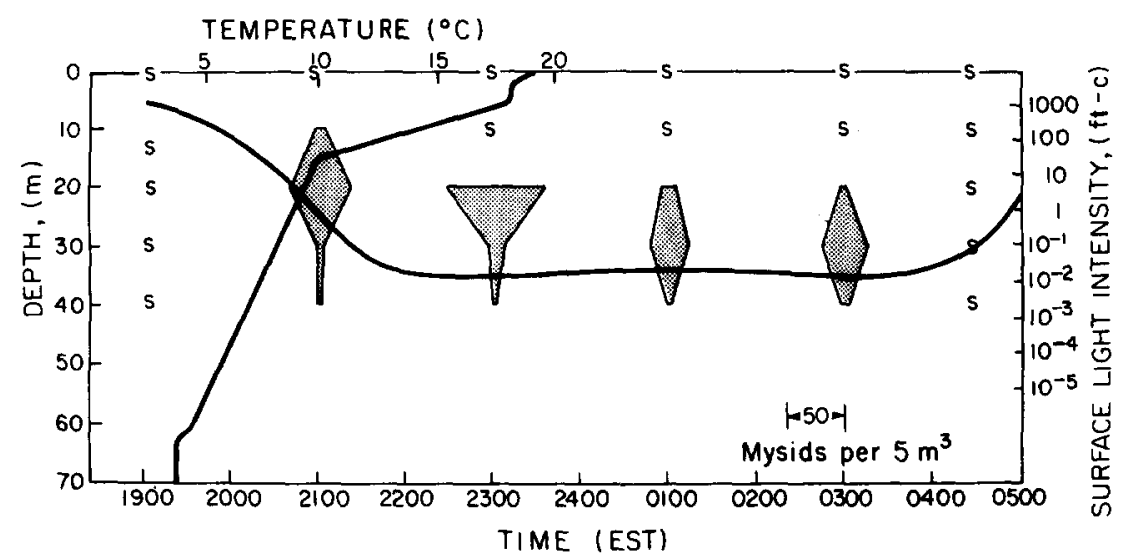

Fig. 1. Vertical distribution of sexually undifferentiated mysids in Lake Michigan, 16-17 July 1954 . Width of polygon indicates number of mysids per 50001 . 'S' indicates a sample that contained no mysids. Temperature is shown by the center curve. The curve extending from left to right shows the surface light intensity. Figure taken from Beeton (1960).

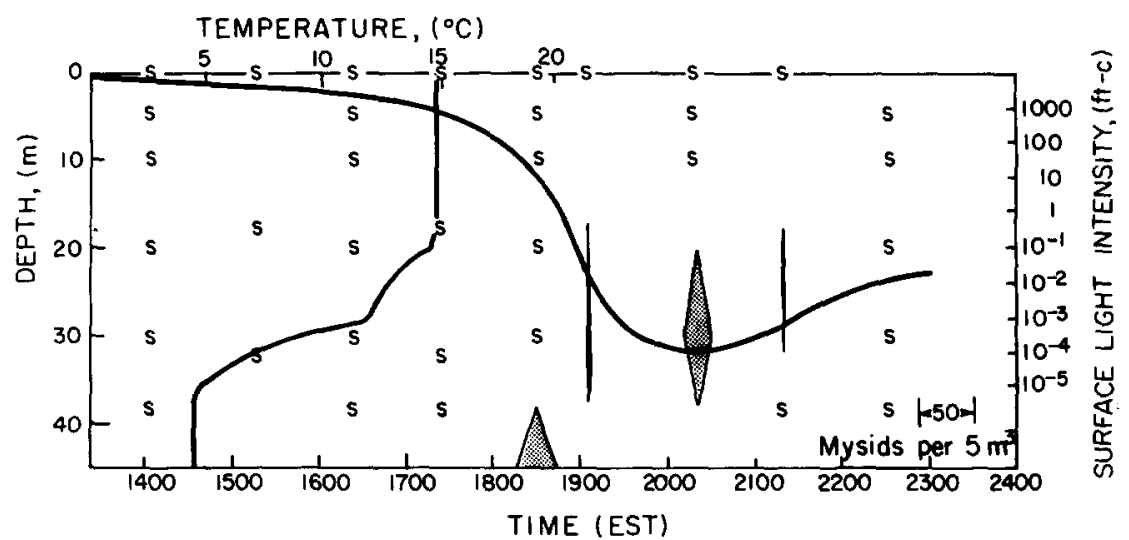

Fig. 2. Vertical distribution of mysids in Lake Michigan, 1954. Symbols and units as in Fig. 1. Figure from Beeton (1957).

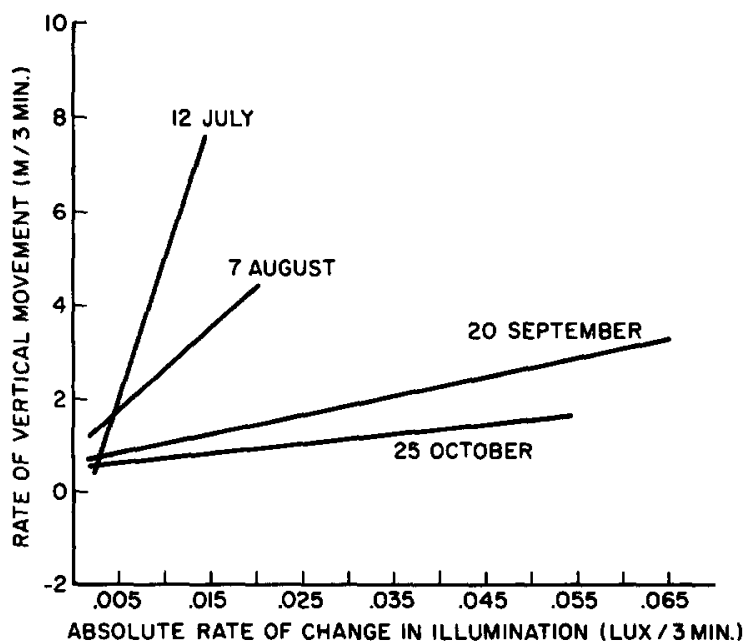

Fig. 3. Relationship between the rate of vertical ascent and the absolute change in illumination. Lines fitted by least squares method. Figure from Teraguchi et al. (1975).
(Fig. 1). These studies showed that the time of ascent was around 2100 EST in June, becoming progressively earlier after the summer solstice, and occurred at 1630 EST in November. The greatest vertical distance of migration closely followed the initial ascent, whereas the time of peak abundance very often was at a greater depth later in the evening. This peak abundance occurred before midnight however, and the mysids subsequently became more widely distributad and fewer in number throughout the water column. Most individuals disappeared from the water column between 0400 and 0500 EST. Mysids usually migrated through the thermocline when first ascending but later in the night they aggregated in or below this layer. Mysids did not migrate through a pronounced 


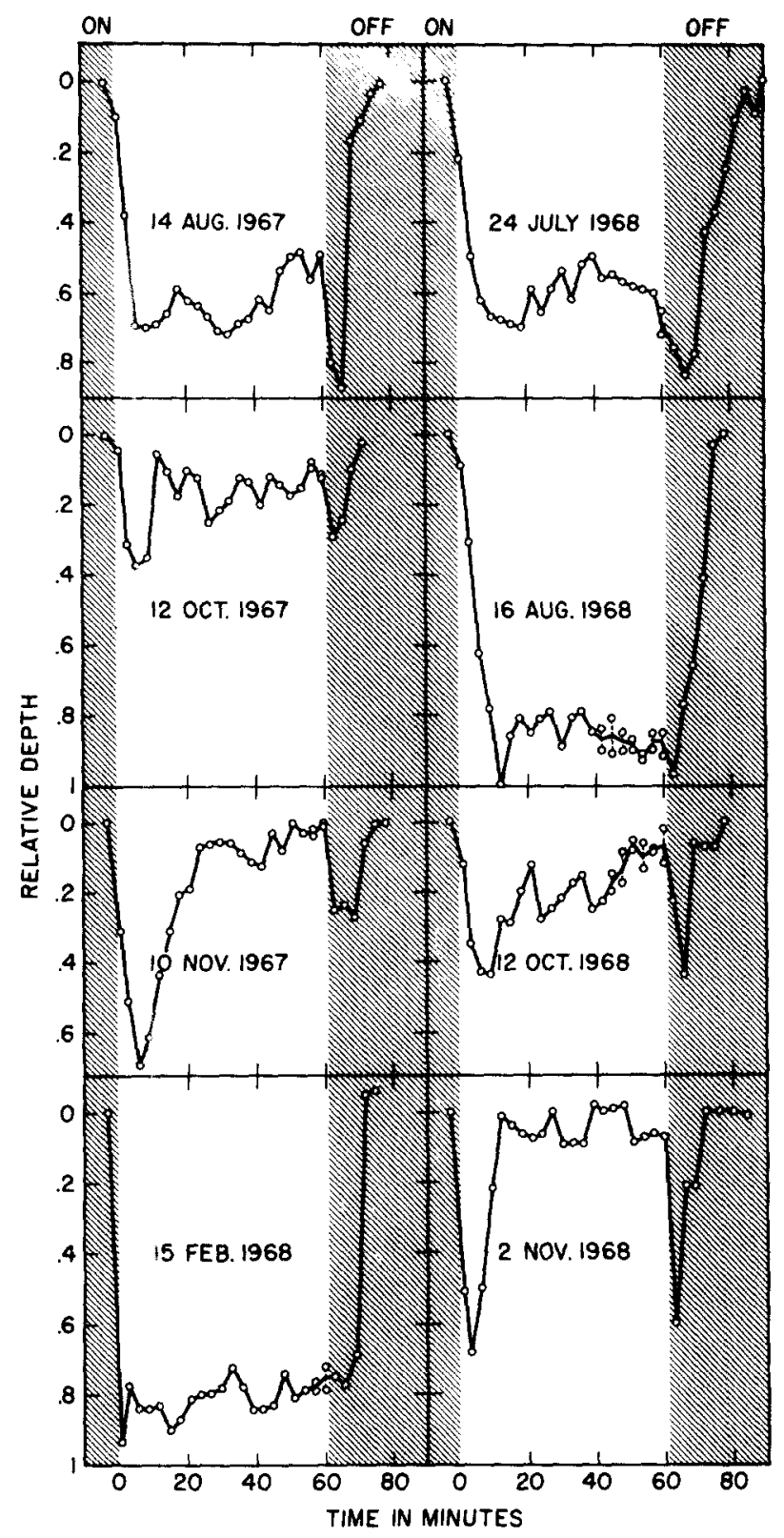

Fig. 4. Displacement pattern of the leading edge in relation to a light cycle consisting of an immediate onset of illumination, constant illumination of long duration and abrupt extinction of illumination. Figure from Teraguchi et al. (1975).

thermocline with temperature gradients of around $2^{\circ} \mathrm{C} \mathrm{m}^{-1}$. When the thermocline was weak or disrupted, mysids were distributed throughout the water column. Their extreme sensitivity to low light intensities was evident on nights with bright moonlight when mysids did not migrate as far upward as on dark nights. On one occasion, when full moonlight developed after initial ascent, the mysids returned to deep water five hours sooner than on dark nights (Fig. 2). The mysids were ascending when surface light intensity was decreasing at approxi-

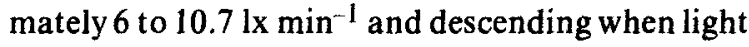
intensity was increasing at approximately 0.032 to $1.3 \mathrm{~lx} \mathrm{~min}^{-1}$. Laboratory studies showed mysids responded to $0.0001 \mathrm{~lx}$ (Beeton 1959).

Teraguchi (1969), using an intensive sampling program and a high frequency echosounder, was able to work out more details of the migratory behavior and more precisely determine times and rates of ascent and descent. His studies demonstrated that age affected migration whereas sexual differences were not important. The onset of ascent was progressively later and onset of descent was progressively earlier with age in both sexes.

The rate of ascent was usually correlated with the rate of absolute decrease in light (Fig. 3), but the rate of descent did not show a significant correlation with increase in light. The slope of the relationship between rate of ascent and rate of change in illumination became progressively less from summer into fall.

His studies also shed some light on mysid behavior during migration. When they were moving upward they appeared to go through periods of rapid ascent alternating with periods of slow ascent or descent. During downward migration they alternated periods of rapid descent with periods of slow descent or ascent.

In situ experiments using various numbers and cycles of artificial light provided additional evidence of the importance of light to the migratory behavior of $M$. relicta (Teraguchi et al. 1975). Abrupt illumination caused the mysids to seek a greater depth, where they remained until the lights were turned off during the winter and summer (Fig. 4). Similar experiments in the fall resulted in the mysids returning to their initial depth. Consequently, no adaptation to increased light occurred in winter and spring, but they did adapt in the fall. A continuous increase and subsequent decrease in light resulted in a progressively downward and then upward displacement in the leading edge of the mysid scattering layer. This was pronounced in the summer, but to a much lesser extent in the fall.

Teraguchi (1969) concluded that the onset of evening ascent appeared to be triggered by rate of 
change in log illumination, although the onset did not always occur at the same level of illumination. The leading edge of its upward migration was associated with light intensity of 0.014 to $0.063 \mathrm{~lx}$, but there appeared to be a seasonal progression in the mean value and range of illumination (Teraguchi et al. 1975).

The echograms obtained by Teraguchi (1969) provide information on details of the vertical migration of $M$. relicta which are difficult to obtain by sampling. The echograms showed the migration and vertical distribution to consist of a major evening ascent (MEA), period of up and down movements - dark oscillations, and a major morning descent (MMD). Other features which occurred on several echograms were a minor evening ascent following the MEA, followed by a late evening descent, an early morning rise, an early morning descent, and a minor morning descent after the MMD.

Beeton (1959) established that $M$. relicta has a peak sensitivity to light at $515 \mathrm{~nm}$ and light in this wave length penetrates farther than other light into the deep waters of the Great Lakes. His studies showed that $M$. relicta was photopositive unless they were subjected to total darkness for ten hours and then they were photonegative. Duplicate experiments with Neomysis americana gave similar results (Herman 1962, 1963). The action spectrum studies showed that mysids swam downward whenever a light of $0.0001 \mathrm{~lx}$ or greater was turned on.

Based on these studies Beeton (1957) concluded that, although $M$. relicta were photopositive during the day, they remained near the bottom because they had a negative response to increased light intensity experienced when they swam upward. The photopositive mysids migrated upward as light intensity decreased at sunset. The upper extent of migration and their behavior was determined by thermal and prevailing light conditions, e.g., moonlight. The descent was a result of their negative phototaxis.

The studies conducted by Teraguchi et al. (1975) lend support to several hypotheses on vertical migration. The fact that the leading edge of the scattering layers was consistently associated with a narrow range of illumination supports the idea of an optimum zone of illumination (Rose 1925) as well as lends support to Siebeck's (1960) conclusion that the rate of vertical movement of zooplankton is related to the rate of absolute change in illumination. One set of observations also fits ideas of McNaught \& Hasler (1964) that there is a linear relationship between rate of movement and rate of relative change in illumination. The apparent seasonal changes in the response of $M$. relicta to illumination led Teraguchi et al. (1975) to suggest the possibility of a circannual rhythm in its photic responses.

The above observations clearly indicate that a changing pattern of illumination is the principle causal mechanism controlling mysid migrations. Recently there has been a renewed interest in the 'ultimate causes' of this behavior in zooplankton, although for the past one hundred years zooplankton ecologists have offered different teleological explanations. Though some involve light (Russell 1927; Harris 1953; Hairton 1976), genetic recombination (David 1961) and population regulation (Wynne-Edwards 1962), most are based upon feeding relationships in pelagic communities. Noting that zooplankton preferred darkness, Fuchs (1882, see Longhurst 1976) first proposed that vertical migration allowed zooplankton to feed on phytoplankton in the surface waters. Worthington (1931) similarly thought migrations resulted from hunger in zooplankton which daily must invade surface waters to feed at night. Hardy (1956) believed migration would enhance the horizontal dispersion of zooplankton bringing them into patches rich with prey. McAllister (1969) proposed that vertical migration optimized herbivorous predation. During daylight hours algal production is free of predation. Migrating zooplankters concentrate their feeding at night before the day's production is lost through respiration. Kerfoot $(1970,1972)$ formulated a numerical model based on path analysis, which indicated that zooplankton biomass remained at depth ranges of light intensities directly proportional to daily primary production. This consequence reduced variation in the zooplankton's food supply by regulating zooplankton feeding pressure according to the algae's ability to reproduce.

The above hypotheses do not easily harmonize with natural selection. More correctly they should be viewed as the consequences of the selective forces which favor vertical migration (Enright 1977). Some proposals easily accommodate Darwinian selection. Since optimal conditions of temperature and food rarely coincide in time and space, McLar- 


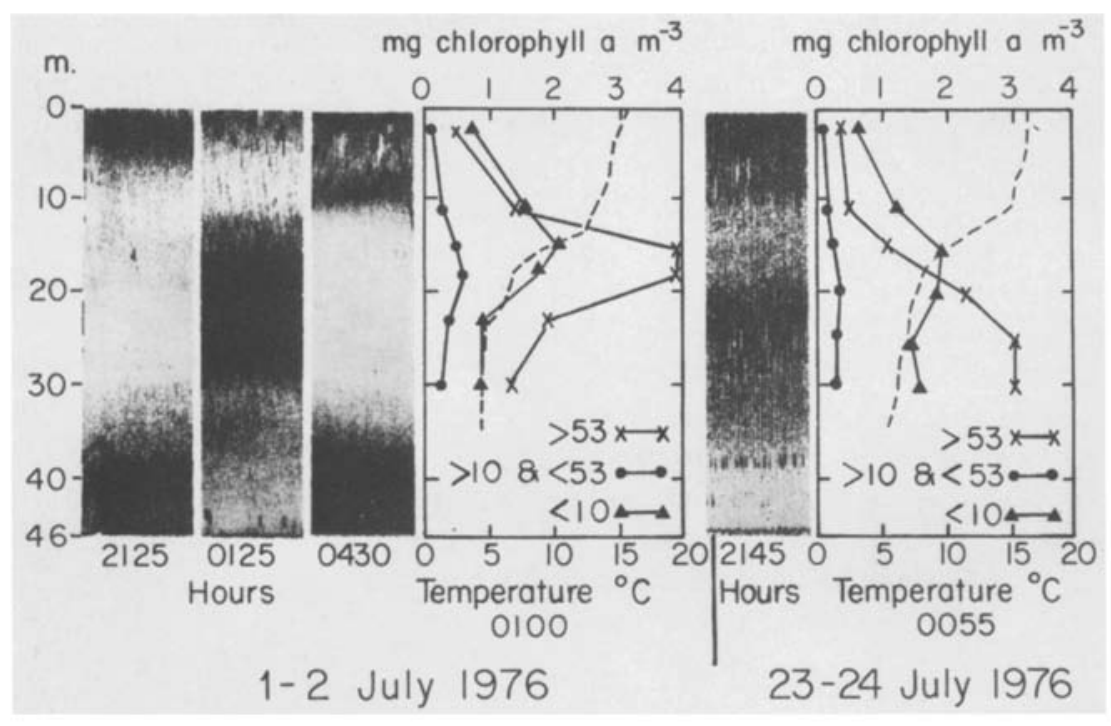

Fig. 5. Echograms of Mysis migration with temperature and size-fractionated chlorophyll a profile for 1-2 and 23-24 July 1976. Time is CDT. Figure from Bowers \& Grossnickle (1978).

en (1963) based his hypothesis on the fact that higher egg production at deeper (colder) depths was offset by retarded development. By feeding only at night in warmer surface waters, marine copepods could maximize their feeding efficiencies at higher temperatures and their growth and development at lower temperatures resulting in an energy (McLaren 1963) or fecundal (McLaren 1974) bonus for the animal. Enright (1977) developed a similar metabolic model following McLaren's approach in that an energy bonus results from migrating in stratified waters. Finally, the perhaps most attractive and widely accepted hypothesis holds that diurnal vertical migration has evolved from the avoidance of zooplankton to daylight where they are vulnerable to visually oriented planktivorous fish. The daily feeding excursions by zooplankton into the food rich surface layers occur at night to avoid fish predation. Zaret \& Suffern (1976) provided the first experimental evidence supporting this hypothesis in Gatun Lake, Panama. The preferred zooplankton prey Diaptomus gatunensis almost always remained at depths where light intensities were too low for the planktivore Melaniris chagresis to feed. Furthermore, this diaptomid exhibited this migration in an unstratified lake in direct contradiction to McLaren and Enright's hypotheses. Finally, when reviewing hypotheses regarding diurnal vertical migration, Miller's (1979) comments are worth noting. The necessary experiments that could prove or disprove any of the above ideas cannot be performed. Thus proposed hypotheses cannot be eliminated and all will remain viable. Miller cautions us to carefully consider any new and competing causes before they join this growing list.

What are the 'ultimate causes' or selective pressures that lead to the pronounced migratory behavior of Mysis? A proper evaluation of the aforementioned hypotheses (McLaren 1963, 1974; Zaret \& Suffern 1976; Enright 1977) compatible with natural selection first assumes some understanding of the relationship between migration and mysid feeding and their own mortality due to fish predator's Several studies link mysid migrations to feeding and one investigation clearly correlates mysid mortality to migrating planktivores.

In Stony Lake, Ontario, Lasenby \& Langford (1973) observed the change in mysid gut contents at two stationary periods in the migration cycle midday and midnight. At midday near the lake bottom the guts contained detritus and algae; at midnight Mysis preyed heavily on Daphnia and the rotifer Kellicottia in the water column. Although this omnivorous behavior has long been observed (Forbes 1882), the carnivory at night was striking.

Rybock (1978) also investigated mysid gut con- 


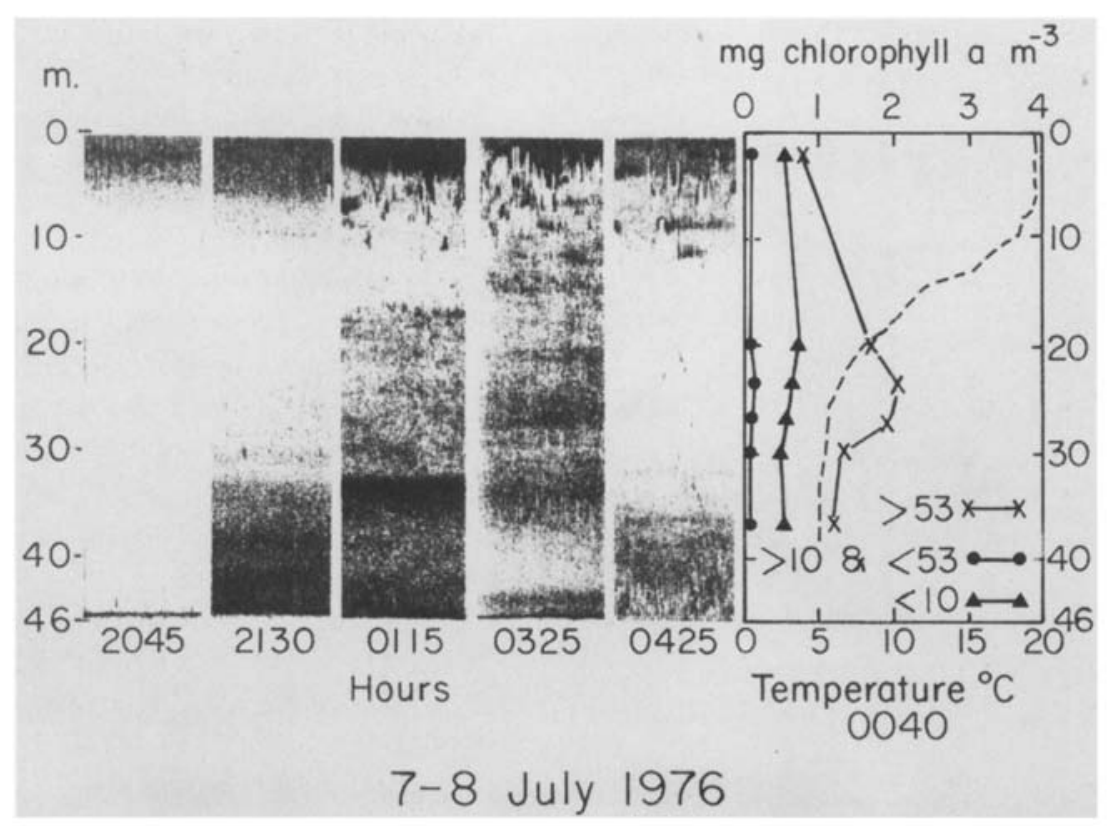

Fig. 6. As Fig. 5 for 7-8 July 1976. Note completed mysid ascent as $0325 \mathrm{~h}$ after a moonset at $0240 \mathrm{~h}$. Figure from Bowers \& Grossnickle (1978).

tents while carefully monitoring the extensive 400-500-m migrations of Mysis in Lake Tahoe where they are holoplanktonic in the deeper areas, preventing any benthic feeding. At night Mysis strongly selected for the copepod Epischura and the cladoceran Bosmina just beneath the thermocline where both prey were found in high concentrations. The population was located well below the thermocline at depths greater than $100 \mathrm{~m}$ during the day where prey densities were significantly lower. During full moon periods mysids remained well below shallower depth strata where prey densities were much higher. Since ingestion rates were proportional to prey concentrations, this suggested moonlight might inhibit feeding rates.

In Lake Michigan where phytoplankton biomass is much greater, Bowers \& Grossnickle (1978) correlated the migratory and herbivorous feeding behavior of Mysis to the vertical structure of phytoplankton during thermal stratification. Using changes in size fractionated chlorophyll as an indicator of grazing, laboratory experiments indicated a preference for large filamentous diatoms. A concurrent field effort coupled the mysid migrations to a deep chlorophyll layer (Brooks \& Torke 1977) where these filamentous diatoms reside in large numbers in and beneath the thermocline. At night a mysid deep-scattering layer, as seen by a high frequency echosounder, resides within the deep chlorophyll layer (Fig. 5). These observations strongly implied that Mysis migrated into a phytoplankton rich stratum where it fed until the predawn descent. On one night a full moon delayed the mysids from their normal evening ascent until moonset in early morning (Fig. 6). Thus for most of the evening the mysids were not located in the deep chlorophyll layer away from this food resource. However, it had not been proved that feeding occurred in this situapion. In a follow-up study Grossnickle(1979), using Mackas \& Bohrer's (1976) in situ technique, assessed mysid gut fullness during migration. Significant increases in gut fullness occurred soon after sunset and guts remained full until the morning descent for all mysid instars (Fig. 7). Therefore Mysis exploits the preferred long-chained diatoms in the deep chlorophyll layers.

If $M y$ sis does receive an extensiva part of its daily food ration in the water column at night, one question which remains unanswered is what does $M y s i s$ do during the daylight hours on lake bottom? Previously Mysis was thought to be a benthic detritivore(Lasenby \& Langford 1973; Grossnickle 1979). Recently Parker (1980) has observed mysid predation upon the burrowing amphipod Pontoporeia 

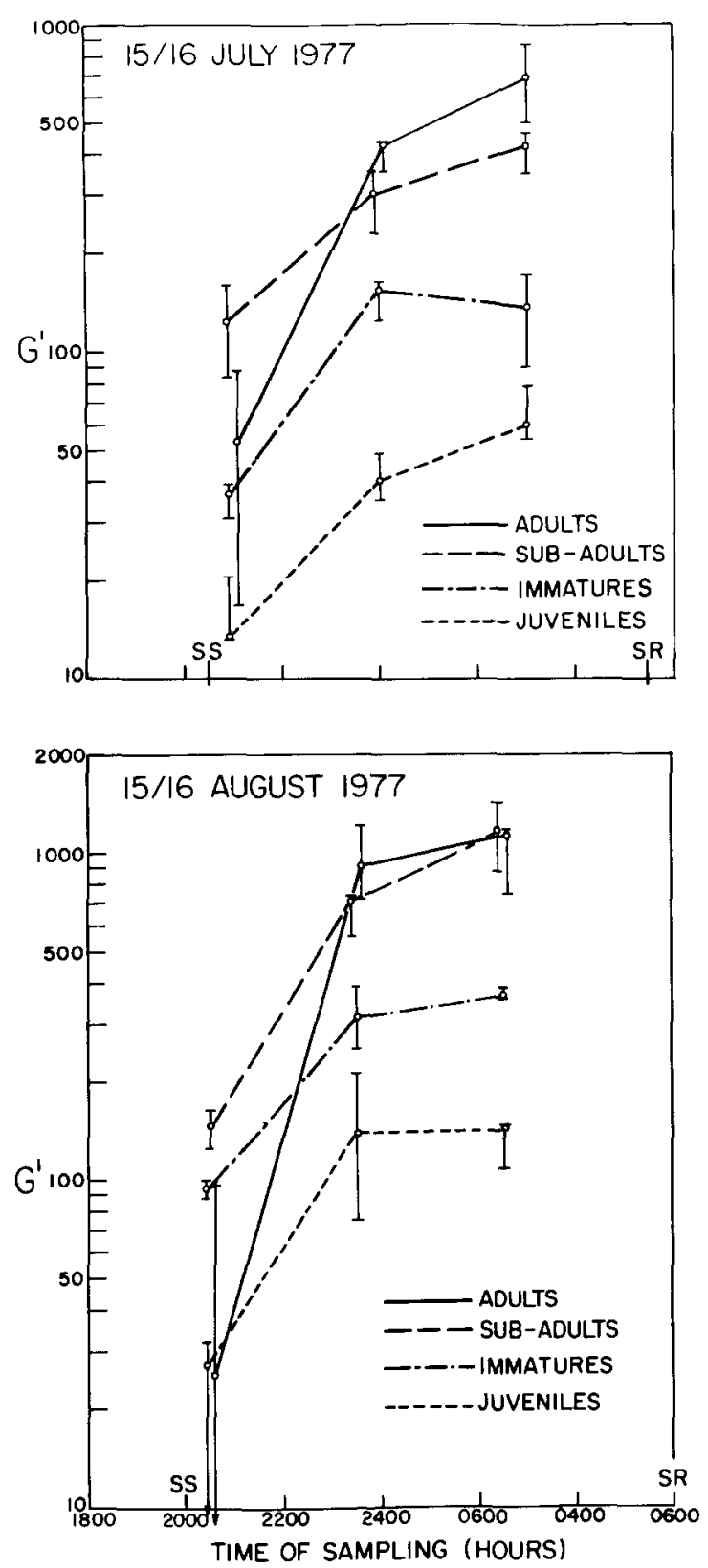

Fig. 7. Nocturnal changes in mysid gut fullness ( $\left.\mathrm{G}^{\prime}\right)$ per Mysis in Lake Michigan. Figure from Grossnickle (1979).

hoyi. This amphipod is primarily a benthic detritivore and an important food resource for demersal fish in the Great Lakes. Significant mysid predation on benthic macroinvertebrates questions the advantage of migrating in order to feed on zooplankton and algae at night. Diurnal vertical migration thus places Mysis on a diel schedule where feeding takes place in two very different communities, the pelagic and the benthic.

All of the above data only portray Mysis as the vertical migrator relative to its prey. In Lake Michigan both a preferred prey group and an important mysid predator also vertically migrate, complicating an understanding of the temporal and spatial aspects of mysid's trophic couplings to the rest of the limnetic community. Cladocerans, especially Daphnia, are a preferred prey group (Cooper \& Goldman 1980), to the point of being nearly vanquished by Mysis in some lakes (Goldman et al. 1979). In Lake Michigan most of the Daphnia population migrates from metalimnetic strata into the top 5-10 at night. Although Mysis feed upon Daphnia at night, they cannot fully exercise their preference since the majority of each group do not precisely coincide in time and space during stratification. Bowers \& Vanderploeg (1982) developed an in situ technique similar to Haney's (1973) where mysids were released into a large feeding chamber after enclosing the natural prey assemblage at a desired depth. All of their experiments were performed just beneath a sharp thermocline where Mysis nightly layers out, and at two stationary phases of the migration cycle midday and midnight. The midnight results indicated low cladoceran prey densities and mysid predation rates. When release at midday, predation rates were significantly higher, corresponding to higher cladoceran prey densities. Cladoceran mortality was reduced by their own vertical migratory behavior.

In Lake Michigan Mysis and its chief predator the alewife have coincident migration patterns (Janssen \& Brandt 1980). Alewife stomach contents revealed these migrations were linked to the planktivores feeding upon mysids. During periods of bright moonlight Mysis remained at deeper strata than normal. Adult alewives also concentrated at the same depth to feed. Janssen \& Brandt (1980) interpreted alewife migration as an adaptive response to their vertically migrating prey.

Having reviewed mysid trophic couplings from the vertical migration perspective, we can again ask what selective pressures led to the evolution of mysid migrations. We agree with Woodhead's (1966) philosophy regarding migration. There may be several selective advantages for a single species with each advantage relatively more important for different age groups or for differnt habitats acting 
singly or simultaneously. Three competing hypotheses discussed earlier are attractive. Migration into depths having high densities of zooplankton prey as in Lake Tahoe or Lake Michigan with a deep chlorophyll layer sustains higher feeding rates which would translate into increased growth and reproduction. During thermal stratification the metabolic models of McLaren $(1963,1974)$ and Enright (1977) conceivably are applicable, especially for juvenile mysids which penetrate further into the thermocline and warmer water. During the daylight hours Mysis inhabits hypolimnetic water of four to six degrees. Maintenance costs are lower than when contrasted to the $10-15^{\circ} \mathrm{C}$ waters mysids feed in at night. Mysis might enjoy an energy or reproductive bonus in this situation. The predation hypothesis is especially attractive in Lake Michigan. Mysis is the largest and most easily seen zooplankton prey to visually hunting planktivores that are size selective (Brooks \& Dodson 1965). Two observations support this review. First, the smaller and less visible juvenile mysid stages generally lead the evening ascent and are the last group to descend in the morning. Second, moonrises and moonsets interrupt the natural migratory cycle. This behavior extracts a significant cost since Mysis spends less time foraging in the metalimnion. Each of the above hypotheses are intuitively inviting but remain untestable (Miller 1979). Future efforts should focus on possible experimental designs to test them.

\section{References}

Apstein, C., 1906. Lebensgeschichte von Mysis mixta, Lillj., in der Ostsee. Wissensch. Meeresunters, N.F., IX. Bd. Abt. Keil, 239-260.

Beeton, A. M., 1957. The vertical migration of Mysis relicta in Lakes Muron and Michigan. Ph.D. thesis, Univ. Mich. 131 pp.

Beeton, A. M., 1959. Photoreception in the opossum shrimp, Mysis rehicta Lovén. Biol. Bull. 116: 204-216.

Beeton, A. M., 1960. The vertical migration of Mysis relicta in Lakes Huron and Michigan. J. Fish. Res. Bd Can. 17: 517-539.

Birge, E. A. \& Juday, C., 1927. Pontoporeia and Mysis in Wisconsin Lakes. Ecology 8: 445-452.

Bowers, J. A. \& Grossnickle, N. E., 1978. The herbivorous habits of Mysis relicta in Lake Michigan. Limnol. Oceanogr. 23: 767-776.

Bowers, J. A. \& Vanderploeg, H. A., 1982. In situ predatory behavior of Mysis relicta in Lake Michigan. Hydrobiologia 93: $121-131$.
Brooks, J. L. \& Dodson, S. I., 1965. Predation, body size, and composition of plankton. Science 150: 28-35.

Brooks, A. S. \& Torke, B. G., 1977. Vertical and seasonal distribution of chlorophyll a in Lake Michigan. J. Fish. Res. Bd Can. 34: 2280-2287.

Cooper, S. D. \& Goldman, C. R., 1980. Opossum shrimp (Mysis relicta) predation on zooplankton. Can. J.Fish. aquat. Sci. 37: 909-919.

Cushing, D. H., 1951. The vertical migration of planktonic Crustacea. Biol. Rev. 26: 158-192.

Dakin, W. J. \& Latarche, M., 1913. The plankton on Lough Neagh: a study of the seasonal changes in the plankton by quantitative methods. Proc. R. Irish Acad, 30(B): 20-96.

David, P. M., 1961. The influence of vertical migration on speciation in the oceanic plankton. Sys. Zool. 10: 10-16.

Enright, J. T., 1977. Diurnal vertical migration: adaptive significance and timing. Part $\mathrm{l}$. Selective advantage: a metabolic model. Limnol. Oceanogr. 22: 856-872.

Forbes, S. A., 1882. On some Entomostraca of Lake Michigan and adjacent waters. Am. Nat. 16: 640-649.

Goldman, C. R., Morgan, M. D., Threlkeld, S. T. \& Angeli, N., 1979. A population dynamics analysis of tha cladoceran disappearance from Lake Tahoe, California-Nevada. Limnol. Oceanogr. 24: 289-297.

Grossnickle, N. E., 1979. Nocturnal feeding patterns of Mysis relicta in Lake Michigan, based on gut content fluorescence. Limnol. Oceanogr. 24: 777-780.

Hairston, N. G., 1976. Photoprotection by carotenoid pigments in the copepod Diaptomus nevadensis. Proc. natn. Acad. Sci. 73: 971-974.

Haney, J. G., 1973. An in situ examination of the grazing activities of natural zooplankton communities. Arch. Hydrobiol. 72: 87-132.

Hardy, A. C., 1956. The Open Sea. Its Natural History: The World of Plankton. Collins, London.

Harris, J. E., 1953. Physical factors involved in the vertical migration of zooplankton. Quart. J. microsc. Sci. 94: $537-550$.

Herman, S. S., 1962. Spectral sensitivity and phototaxis in the opossum shrimp. Neomysis americana Smith. Limnol. Oceanogr. 8: 228-238.

Herman, S. S., 1963. Vertical migration of the opossum shrimp Neomysis americana Smith. Limnol. Oceanogr. 8: 228-238.

Holmquist, C., 1959. Problems on marine glacial relicts on account of investigations on the genus Mysis, Lund. Berklinska Bokorychereit. 270 pp.

Janssen, J. \& Brandt, S. B., 1980. Feeding ecology and vertical migration of adult alewives (Alosa pseudoharengus) in Lake Michigan. Can. J. Fish. aquat. Sci. 37: 177-184.

Kerfoot, W. B., 1970. Bioenergetics of vertical migration. Am. Nat. 104: 529-546.

Kerfoot, W. B., 1972. Reply to Miller et al. 1979. Am. Nat. 106: 548-553.

Langford, R. R., 1938. Diurnal and seasonal changes in the distribution of the limnetic Crustacea of Lake Nipissing, Ontario. Univ. Toronto Stud., biol. ser., No. 45. Publ. Ontario Fish. Res. Lab. 56: 1-142.

Larkin, P. A., 1948. Pontopereia and Mysis in Athabaska, Great Bear, and Great Slave Lakes. Bull. Fish. Res. Bd Can. No. 78. 
Lasenby, D. C. \& Langford, R. R., 1973. Feeding and assimilation of Mysis relicta. Limnol. Oceanogr. 18: 280-285.

Longhurst, A. R., 1976. Vertical migration. In: Cushing, P. H.\& Walsch (Eds.) The Ecology of the Seas. W. B. Saunders, Philadelphia.

Mackas, D. \& Bohrer, R., 1976. Fluorescence analysis of zooplankton gut contents and an investigation of diel feeding patterns. J. exp. mar. Biol. Ecol. 25: 77-85.

McAllister, C. D., 1969. Aspects of estimatijg zooplankton production from phytoplankton production. J. Fish. Res. Bd Can. 26: 199-220.

McLaren, I., 1963. Effects of temperature on the growth of zooplankton, and the adaptive value of vertical migration. $J$. Fish. Res. Bd Can. 20: 685-727.

McLaren, I., 1974. Demographic strategy of vertical migration by a marine copepod. Am. Nat. 108: 91-102.

McNaught, D. C. \& Hasler, A. D., 1964. Rate of movement of populations of Daphnia in relation to changes in light intensity. J. Fish. Res. Bd Can. 21: 291-318.

Miller, C. B., 1979. Comments from a nominate referee on an exchange of notes. Limnol. Oceanogr. 24: 785-787.

Otterstrom, A., 1910. Beobachtungen über die senkrechten Wanderungen des Mysis bestandes in der Ostsee bei Bornholm. Medd. Comm. Havundersög. Kjob., Series: Plankton Bd. 1: 1-10.

Parker, J. I., 1980. Predation by Mysis relicta on Pontopereia hoyi: a food chain link of potential importance in the Great Lakes. J. Great Lakes Res. 6: 164-166.

Rose, M., 1925. Contribution à l'étude de la biologie du plankton: le problème des migrations verticales journalières. Arch. Zool. expér. génér. 64: 387-542.

Russell, F. S., 1927. The vertical distribution of plankton in the sea. Kiol. Rev. 2: 213-262.
Rybock, J. T.( 1978. Mysis relicta Lovén in Lake Tahoe: vertical distribution and nocturnal predation. Ph.D. thesis, Univ, of California, Davis, CA. 116 pp.

Siebeck, O., 1960. Untersuchungen über die Vertikalwanderung planktischer crustaceen unter Berücksichtigung der Strahlungsverhältrisse. Int. Rev. ges. Hydrobiol. 45: 381-454.

Southern, R.\& Gardiner, A. C., 1926. A preliminary account of some observations on the diurnal migration of the crustacea of the plankton of Lough Derg. Int. Rev. ges. Hydrobiol. 15: 323-326.

Southern, R., 1932. The diurnal migrations of the Crustacea of the plankton in Lough Derg. Proc. Roy. Irish Acad. 40: 121-159.

Tattersall, W. M. \& Tattersall, O. S., 1951. The British Mysidacea. R oy. Soc. London.

Teraguchi, M., 1969. Diel vertical migration of Mysis relicta (Lovén) In Green Lake, Wisconsin. Ph. D. thesis, Univ. Wisc. 229 pp.

Teraguchi, M., Hasler, A. D. \& Beeton, A. M., 1975. Seasonal changes in the response of Mysis relicta Lovén to illumination. Verh. int. Verein. Limnol. 19: 2989-3000.

Van Beneden, P. J., 1861. Recherches sur la faune littorale de Belgique, Crustacés. M. Hayez, Bruxelles. 174 pp.

Woodhead, P. M. J., 1966. The behavior of fish in relation to light in the sea. Oceanogr. Mar. Biol. Ann. Rev. 4: 337-405

Worthington, E. B., 1931. Vertical movements of freshwater macroplankton. Int. Rev. Hydrobiol. 25: 394-436.

Wynne-Edwards, V.C., 1962. Animal Dispersal in Relation to Social Behavior. Oliver and Boyd, New York.

Zaret, T. M. \& Suffern, J. S., 1976. Vertical migration in zooplankton as a predator avoidance mechanism. Limnol. Oceanogr. 21: 804-813. 